\title{
Improper or Incorrect Procedure or Method
}

National Cancer Institute

\section{Source}

National Cancer Institute. Improper or Incorrect Procedure or Method. NCI Thesaurus. Code C62862.

Problem associated with the use of the device in terms of nonconforming to that device's intended use, specifications, procedure and process or service instructions and information provided by the device manufacturers. 